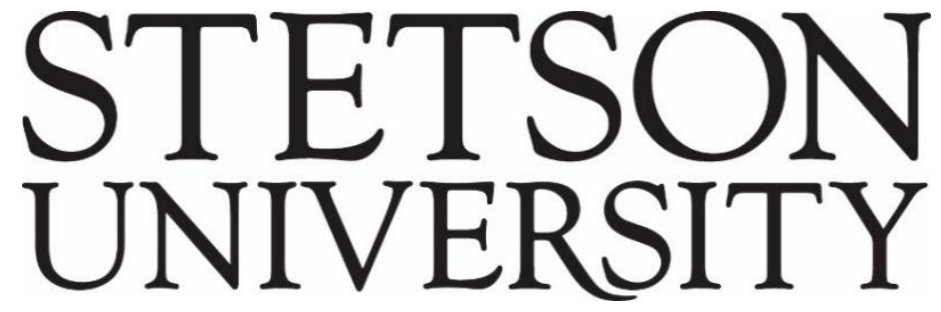

Voices of Reform: Educational Research to Inform and Reform

Volume $3 \bullet$ Issue 2 • Article 4

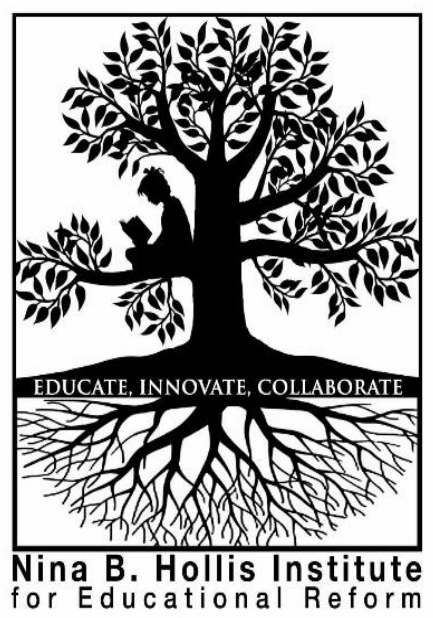

December 2020

\title{
Perceptions of Leadership Identification: A Collective Autoethnographical Study
}

Christopher M. Parfitt

Florida Gulf Coast University

Brianne M. Lopez-Romano

University of West Florida

Danielle M. Hudzina

Charlotte County Public Schools

Sarah G. Rogozinski

Florida Gulf Coast University

Follow this and additional works at: http://www.voicesofreform.com

Recommended Citation

Parfitt, C., Romano, B., Hudzina, D., \& Rogozinski, S. (2020). Perceptions of leadership identification: A collective autoethnographical study. Voices of Reform, 3(2), 82-95. Retrieved from

https://www.voicesofreform.com/article/18596-perceptions-of-leadership-identification-a-collective-

autoethnographical-study doi: 10.32623/3.10006

$\underline{\text { http://dx.doi.org/10.32623/3.10006 }}$

Revisions

Submission date: February $5^{\text {th }}, 2020$

$1^{\text {st }}$ Revision: April $28^{\text {th }}, 2020$

Acceptance: May $11^{\text {th }}, 2020$

Publication date: December $29^{\text {th }}, 2020$ 


\title{
Perceptions of Leadership Identification: A Collective Autoethnographical Study
}

\author{
Christopher M. Parfitt ${ }^{1}$ \\ Brianne M. Romano ${ }^{2}$ \\ Danielle M. Hudzina ${ }^{3}$ \\ Sarah G. Rogozinski ${ }^{4}$ \\ ${ }^{1}$ Southern Regional Council on Educational Administration, United States \\ parfitt527@hotmail.com \\ ${ }^{2}$ College of Education and Professional Studies \\ University of West Florida, United States \\ b121@students.uwf.edu \\ ${ }^{3}$ Charlotte County Public Schools, United States \\ danielle.hudzina@yourcharlotteschools.net \\ ${ }^{4}$ Prince William County Schools, United States \\ srogozinski@gmail.com
}

\begin{abstract}
Through a collaborative autoethnographic approach, a former principal, current principal, current assistant principal, and aspiring principal recount their experiences pertaining to identification of leadership talent. As identified through previous research, proper identification or talent is the first major component to quality succession planning. Data were collected through individual reflections and group discussions and triangulated to published documents from the school district. Positive and negative aspects were identified, including personal experiences and perceptions of district-wide initiatives. Divergent viewpoints were most notable among levels of experience. The former principal focused on systems aspects, the current principals concentrated on aspects that affected them directly or in which they had influence. The aspiring principal addressed the issues from the point of view of a teacher who had limited exposure to several aspects. Limitations and potential biases were acknowledged and recommendations for future research were provided, including expansion as a case study or phenomenology.
\end{abstract}

\section{Keywords}

leadership identification, educational leadership, leadership development, leadership preparation, leadership succession 


\section{Identifying Leadership Talent}

While the growing need for the proper identification of talent is well-documented in business and medical literature (Beeson, 1998, 2000; Beglinger, 2013; Chavez, 2011; Griffith, 2012), there is a lack of research into the identification processes for educational leadership succession (Parfitt, 2017a, 2017b). The lack of defined processes may be a barrier to the development and implementation of sound succession plans and may help explain why school districts often still use an outdated replacement model to fill vacancies, if a plan is developed at all (Parfitt, 2017a). Beeson (2000) asserted that businesses had determined replacement planning was inadequate in the 1990s. Replacement planning was a concept in which one or more predetermined successors were identified and no other options were considered. Succession planning and identification of talent are defined in subsequent sections. Furthermore, specific functions of talent identification are addressed in greater detail, including: (a) finding and cultivating talent from within the organization, and (b) leadership development for emerging talent.

\section{Research-Based Best Practices}

Because a substantial number of individuals involved in education were not familiar with researchbased best practices, to provide clarification and also serve as a reference and an aid for our data collection, a basic list of research-based best practices was compiled and used. A list of researchbased best practices and the literature sources, included:

- Metrics in place to identify talent early and foster development (Griffith, 2012)

- Identification processes should consider future organizational need, and examine beyond the next promotion (Rothwell, 2005)

- Evaluation consists of multiple measures (two levels above and below, peers, as well as external constituents) (Rothwell, 2005), not just a recommendation from one direct supervisor (Beeson, 1998)

- Talented individuals are not held back because of a perceived loss in a current position (Beeson, 1998)

- Identified individuals have vision with passion, integrity, and courage (Chavez, 2011)

- Identified individuals should display open-mindedness, being willing to take risks, but also learn from mistakes (Chavez, 2011)

- Must be trustworthy, value-driven, and authentic (Chavez, 2011)

- Cross-functional identification exists (probably more important for central-office position, could be evident at the secondary level) (Beeson, 2000)

- Qualified, internal candidates are identified (Rothwell, 2005) 
- Future career aspirations are discussed with all employees by a supervisor (Beeson, 1998)

- Organizational culture was considered for leadership decisions (Parfitt, 2017b)

\section{Succession Planning and Leadership Capacities}

Unfortunately, many individuals in educational settings were not aware of succession-planning principles or best practices, which is a problem for creating and improving processes for school and district leadership (Parfitt, 2017b). Succession planning is defined as a comprehensive process by which qualified individuals are identified and prepared to assume positions of greater responsibility at all levels of an organization (Beeson, 1998; Chavez, 2011). Although varying authors have identified multiple components to proper succession planning (e.g., Rothwell, 2005), the process can be viewed in three distinct phases: (a) proper identification, (b) specific development and mentoring, and (c) retention of high-performing individuals (Chavez, 2011; Griffith, 2012). For success during each phase, the unique and specific organizational culture must be considered (Parfitt, 2017a). Rothwell (2005) described the process as integrated and should have a substantial connection to the organization's goals and objectives. Through the successionplanning process, individuals need to develop the knowledge and skills to foster continued growth for the organization. Those individuals may be internal or external candidates, as there are challenges and benefits to both (Sabina \& Colwell, 2018). Furthermore, Smeltzer (2002) believed there was a moral imperative to prepare individuals for positions of greater authority, knowing that some will leave to accept positions with other entities.

\section{Defining Identification of Talent}

When considering the unique organizational culture, the process for talent identification should be multifaceted. Rothwell (2005) recommended a focus on performance management, which contains aspects of work and the environment to assess performance in the past and present, as well as predict the future. Rather than performance appraisal, which contains a narrow focus on past performance. Senior leaders need to identify individuals with great potential, not just those who are exemplary in a current or past position (Rothwell, 2005). Identification processes need to be robust, which include feedback from a direct supervisor, direct subordinates, superordinates and subordinates two levels removed, peers, and individuals external to the organization (Beeson, 1998). Regardless of the positions, Rothwell (2005) contended that executive-level leaders needed to be intimately involved in the process. Gurchiek (2015) further opined that human resources leaders were responsible for warning senior leaders about a lack of succession planning.

The worst method for talent identification is the reliance on a singular recommendation from a direct supervisor (Beeson, 1998). Unfortunately, in education literature, some have erroneously reported that talent identification for future school principals resided solely with the current principal (e.g., Hengel, 2007; Steele, 2012; Thomas, 2011). The determination was a result of interviews with a very limited number of senior leaders, not a reliance on best practices. Because of the unfamiliarity with research-based best practices, many school leaders believed they were engaged in quality success practices, when their actions were truly the exact opposite (Parfitt, 2017b). 
In traditional models, the concept of replacement planning was utilized in which one individual was recognized to replace a senior leader. Uncertainty and changing environments forced senior leaders to abandon traditional models of succession planning at the turn of the $21^{\text {st }}$ century (Beeson, 2000). Although other fields were adapting to new challenges, Riddick (2009) asserted that educational leaders were slow to embrace succession planning. In confirmation of Riddick's assertion, Zepeda et al. (2012) suggested that school leaders begin to use replacement planning as part of the succession process, when Beeson (2000) described replacement planning as an outdated and ineffective concept over a decade prior.

Best practices for talent identification include processes to identify individuals who are adept at listening to others, open-minded, trustworthy and authentic, willing to admit failures, willing to take risks, and visionary (Chavez, 2011). However, Chavez (2011) posited that far too often identification metrics were limited to current job success or identification of charismatic individuals. Beeson (1998) warned that emotional factors contributed to poor candidates being rated highly and highly skilled employees being rated lower than deserved. A desire to keep an effective employee in the same position was also a contributing factor to ineffective identification. To address the issues, Beeson (2000) asserted that effective organizational leaders frequently used cross-functional assessments. A concept that is often foreign to school leaders.

\section{Finding and Cultivating Talent from Within the Organization}

The process of talent identification for positions of leadership should begin with entry-level employees. Those with the proper knowledge, skills, and dispositions should be hired and then trained eventually to assume positions of greater authority (Griffith, 2012). Having a pool of prepared, qualified candidates is preferable to having a vacancy with no one ready to assume the position (Beglinger, 2013).

Griffith (2012) and Rothwell (2005) included the importance of effective assessment to identify leadership talent. Before dispositions can be assessed, dispositions must be defined. Wilkerson and Lang (2011) described dispositions as the values, beliefs, and attitudes held by an individual. Although their focus was the preparation of leadership candidates through an academic setting, assessment of dispositions provided an avenue for program improvement and a basis from which to train future school leaders (Parfitt, Rea, Carter, Wilkerson, Rose, \& Valesky, 2019; Parfitt, Rea, Carter, Wilkerson, \& Valesky, 2017a, 2017b; Rea, Carter, Wilkerson, Valesky, \& Lang, 2011). Identifying dispositions for future leaders serves as a basis for talent identification, as well as aspects on which to focus professional development.

As Beeson (1998) warned, the reliance on feedback from one direct supervisor was the poorest choice for talent identification, and he later added that identification decisions should include cross-functional assessment (Beeson, 2000). Rothwell (2005) expanded upon the point by stressing the importance of including multiple individuals. The assessment should include feedback from direct supervisors and subordinates, those two levels above and below, colleague and peers, as well as competent external reviewers. Unfortunately, educational researchers have erroneously reported that the principal should be the sole source of identification, including a belief from senior-level leaders that the responsibility resided with the school principal (Hengel, 2007; Steele, 
2012; Thomas, 2011). Another issue with talent identification resides in the fact most teachers who enroll in graduate-level leadership program self-select to begin a degree program. To combat selfselection, collaborative partnerships are needed, and specific guidelines should be established to document competency, including meeting state-mandated requirements (Brittingham, 2009).

\section{Leadership Development for Emerging Talent}

Although identification and development are distinct aspects, there is substantial overlap among the components for proper succession planning (Chavez, 2011). Emerging talent must be cultivated appropriately. Beeson (1998) warned against providing generic management training as a substitute for individualized professional development. As an example of a quality process, Durden, Izquierdo, and Williams (2008) examined a new administrators' program for the New York City School System. All applicants completed multipronged assessments, and those selected received individualized development plans that were targeted and specific for their needs and skills and also matched to a specific mentor for two years.

Conger and Fulmer (2003) recommended a systems-approach to develop those identified as future leaders. In addition to formal training and development programs, mentoring-formal and informal-were vital to success (Chavez, 2011). One of the surprising findings was the greater reliance on informal mentoring by current and aspiring leaders (Parfitt, 2017b). Because of the flexibility inherent to an informal process, school leaders should serve as mentors to promising individuals and help prepare them for future leadership position (Parfitt \& Rose, 2020). Unfortunately, as Parfitt (2017b) found, school leaders infrequently used best practices for succession planning, which included talent identification and mentoring.

\section{Research Design and Methodology}

Because the process of leadership talent identification involves recognition of patterns and interactions, Muncey (2010) described an autoethnographic study as an investigation of multiple layers of consciousness involving the vulnerable and coherent self, critiquing the social context and discourses. Although Creswell (2013) listed a challenge in completing an ethnographic study as a need to understand the cultural anthropological aspects and meaning in the cultural subsystems, as embedded researchers have an intricate understanding of the socio-cultural aspects of a school and how they are shaped by educational leaders. Therefore, the greater challenge was to admit our biases and understand the influences so we could examine the process objectively. However, Chang (2008) asserted that the heart of autoethnographic research is personal data. Maso (2001) and Ellis and Bochner (2000) contended that autoethnographic research ranges from purely personal experiences to a parallel exploration of the researcher and other participants. Using Mendez's (2013) assertion that autoethnographic research lacks formal regulations, because the importance of the research is the meaning, not the production; therefore, we undertook this research as a collaborative approach. Ellis and Bochner (2000) did not address the concept of a collaborative autoethnography; however, they asserted the importance of involving other people to conduct reliability checks. Differing from co-constructed approaches, in a collaborative autoethnography, the combined experiences of the researchers are used to demonstrate a community perspective to an issue (Ellis, Adams, \& Bochner, 2011). 


\section{Research Questions}

To address the issue of leadership identification, our study was informed by one general research question:

- In what ways have current and former school administrators and administrative candidates experienced leadership talent identification?

\section{Data Collection}

"A hallmark of all good qualitative research is the report of multiple perspectives that range over the entire spectrum of perspectives" (Creswell, 2013, p. 151). For an autoethnographical study, Creswell (2013) recommended taking a biographical memoir approach to data collection. Although his focus was primarily phenomenological research, Englander (2012) believed qualitative data collection and analysis be viewed as one seamless process. The viewpoint is echoed in that data collection is not only a process, "but also evaluating and organizing data" (Chang, 2008, p. 76). Our data consisted of self-reflections and transcripts of group discussions. As Muncey (2010) clearly asserted for autoethnographical research, there is a need to be selfcritiquing while assessing the social aspects of the problem. Because of the involvement of multiple researchers, we used an approach defined as a collaborative autoethnography (Chang, Longman, \& Franco, 2014). Ngunjiri, Hernandez, and Chang (2010) contended that collaborative methods ranged on a continuum from research segmented partially by stages or time, to fully concurrent collaborative. Although a fully collaborative approach was used, the individual datacollection phase was vital, as Chang, Ngunjiri, and Hernandez (2013) indicated that self-reflection was a critical component to collaborative inquiry.

Ellis, Adams, and Bochner (2011) specified that approaches to autoethnographic work vary by the emphasis placed on the researcher, interactions, and relationships. What they described as a community autoethnography is the process we used and defined as collaborative autoethnography in which the researchers collaborate using personal experiences to document a cultural or social issue. A collaborative approach may foster opportunities for intervention to address the social or cultural issue. For collaborative autoethnography, two or more researchers collect and analyze autobiographical data to interpret the meaning within the context of the sociocultural experiences. They described the process as iterative with self-reflexivity with the result having a unique harmony and synergy that individual autoethnographic approaches lack (Chang et al., 2014). Hernandez, Chang, and Ngunjiri (2017) specified that collaborative autoethnography had gained greater acceptance as evident by increased publications in a variety of scholarly journals because researchers have the potential to provide authentic and rigorous studies with a level of personal depth that cannot be matched by other research methodologies.

\section{Data Analysis}

Using NVivo Pro, all data sources were compiled and then coded for themes. Analysis included reading, rereading, and searching and coding for initial themes. Through the use of axial coding, the initial themes were reviewed to determine relationships and connections among the open-coded 
themes (Strauss \& Corbin, 1998). To mitigate bias, in accordance with the recommendations by Chang et al. (2013), each author completed a self-reflection without discussing memories or recollections with the others. After individual reflections were completed, we met as a group to discuss our collective experiences and assess our recollections through Muncey's (2010) socialaspects lens. As Marshall and Rossman (1999) contended, once data are coded, the researcher must test emergent understandings, as negative patterns may emerge. An exploration of alternative explanations must be considered before writing.

An external reader with expertise in leadership development and qualitative research was employed to examine the transcripts and coded themes, and determined the conclusions were appropriate. Because the data sources were limited to our self-reflections and group discussion, triangulating the findings was difficult. The most objective measure to triangulate data was to review administrative appointments over a one-year period. One author specifically recalled a statement from a senior administrator specifying that appointments for positions as head principal should be limited to those with seven or more years of experience as an assistant principal, yet several appointments were made of individuals with only three- or four-years' administrative experience. A similar review of appointments of teachers to assistant principal yielded that often highly effective teachers serving in curriculum specialist and instructional support positions, who also had advanced graduate degrees, were often passed over in favor of candidates with lesser experience and credentials, but who had some known political connection. Albeit limited, triangulation served as a component to ensure verisimilitude. The use of an external reader was also an appropriate step for providing validity and reliability (Creswell, 2013). Golafshani (2003) asserted that trustworthiness was crucial for validity and reliability in qualitative research; however, triangulation methods are not fixed for all qualitative research and change depending upon the criteria of the study. Therefore, our focus was to understand researcher bias, and the way in which it can influence data. Chang et al. (2013) stated, the focus on data interpretation was critical for collaborative autoethnography.

\section{Study Context and Participants}

The four authors are at varying stages in holding school-leadership positions, as one is a former school administrator with experience at the elementary and secondary levels, one is a current elementary principal who also has teaching experience at the secondary level, one is a current secondary-level assistant principal with administrative experience at the elementary and secondary levels, and one is an aspiring leader with teaching experience at the secondary level. Although never concurrently and not presently, all participants were employed by the same school district at one time, and they previously lived in the same geographic area in the southeastern United States.

\section{Limitations}

Qualitative research has a general limitation for generalizability. All authors live or previously lived in the same geographic area and were employed by the same school district at one time (although not concurrently); though, all have experience in other K-12 educational settings. The 
study was limited to our perceptions and recollections of leadership identification in school settings, and despite attempts to identify and understand, our biases may still be subtly present. Although, Ngunjiri et al. (2010) asserted that a collaborative approach to autoethnography provided greater accountability than solo research. Additionally, the sources of data were limited to personal reflections and group discussion, few external data sources were available for triangulation purposes.

\section{Discussion}

The findings included positive and negative experiences with leadership identification. Most of the findings were situational. Through our experiences and recollections, we believed that some school leaders excelled at identifying talent, while others did not. District-based pool programs had mixed comments. The practicing principals believed the processes were rigorous and only the truly prepared candidates excelled, while others were very disappointed with the results. However, all findings confirmed Parfitt's (2017b) findings; organizational culture was not considered at a system level, and inclusion only occurred if an individual school leader addressed culture during a personalized component in the process.

As to be expected, the differences in level of experience contributed to the view of the leadership identification. The authors in current school-based leadership positions had a greater focus on how they identify talent and encourage future leadership candidates. The author who is an aspiring leader had a narrower focus on the self-selection aspect, but appreciated the support shown by school leaders to allow her to grow professionally. The author who is a former school leaderalso had central-office experience-focused on the "bigger picture" and primarily addressed the lack of systems processes.

Among the group discussion, weaknesses in the overall system were discussed at length, as politics and extraneous factors were often deciding factors, not potential to succeed as a leader. Supposedly objective metrics, including evaluation scores and student growth measures were rarely considered for administrative promotions. Even requirements for minimum time as an administrator were waived for a chosen few. In some instances, administrators were placed in schools over the objections of parent and community groups. A quote from the former principal captured the essence:

From my perspective, few formal methods were used. From a district level, official pools were used, yet administrators often remarked about the low quality of individuals in the pools. Unfortunately, most administrative positions were truly filled before a vacancy was posted. Too many unqualified individuals were promoted, while truly exceptional ones did not even receive interviews, and in turn, many left the organization.

\section{Study Context and Participants}

As Parfitt (2017b) previously found, too many school leaders believed they were engaged in proper planning for leadership succession, while their actions directly contradicted best practices. All four 
of us agreed there were no formal processes for identifying future leadership talent. We had experienced limited instances of a principal recommending a specific teacher enroll in a leadership program, but those instances occurred infrequently and on an individual basis; there was no systematic process. Although changes in state certification requirements made leadership preparation programs verify candidates for advanced degrees have minimal documented effective teaching experience, those enrolling in leadership preparation programs self-selected. As Brittingham (2009) contended, self-selection for leadership candidates is an ineffective process. On a limited basis, some principals did support teachers who were aspiring leaders and provided learning opportunities, but only after admission into a leadership program. The aspiring leader described the experience:

Once I pursued leadership (I wouldn't say I was "identified" since I took the initiative), I felt that my character played a big part in being given so many leadership opportunities. It was clear that vision, integrity, passion, and willingness to learn from mistakes were highly valued. I never once felt I would be negatively affected by pursuing leadership, but instead I enjoyed my classroom position more when given new responsibility at the school.

Despite the fact school leaders need to have a vision and anticipate future organizational needs (Owens \& Valesky, 2015), we had no experiences of processes or programs designed to meet future needs. The school districts had pool programs for which an individual had to qualify before being eligible for a leadership position. However, those programs did not address specific organizational culture, served as a type of "quality check" and were not intended to help prepare individuals for greater positions of authority. For certain individuals, we had seen that pool requirements were waived completely; whereas, for other individuals, entry into the pool was delayed and therefore those individuals were not eligible to apply for open positions.

One of the most important aspects found in succession-planning literature from other disciplines was the focus on obtaining multiple perspectives for talent identification (Beeson, 1998, 2000; Griffith, 2012; Rothwell, 2005). Furthermore, Beeson (1998) asserted that the worst indicator for future potential is the reliance on the recommendation from a direct supervisor; yet, all four of us recalled several instances in which the only person who made the decision was the direct supervisor, or worse yet, the principal's supervisor made the decision without consultation. The finding is not surprising, as Parfitt (2017b) noted that when multiple individuals were involved in talent identification, the principal and senior administrators were the only ones with input.

\section{Use of Best Practices}

Based on research-based, best practices for leadership identification, there were no formal processes used to identify talent early and provide targeted development (Griffith, 2012). Because there were little to no systematic activities, most of our experiences were individualistic. For example, Beeson (1998) asserted that in quality succession-planning initiatives, high-performing individuals are not held back because a perceived loss for a current position. Of the three authors who are or were school-based administrators, we had observed some principals who were 
proactive at helping subordinates succeed, while others were vindictive toward teachers who aspired to greater positions of authority. The aspiring principal had a positive experience with school leaders helping others. As an example of individualistic practices, the current principal believed in the importance of leadership, and thus provided growth opportunities, and described as "I mentor, offer opportunities, and have crucial conversations about leadership tasks, issues, etc..."

Having proper dispositions was paramount for success in a school leadership position (Wilkerson \& Lang, 2007). Without identifying as dispositions, Chavez (2011) asserted that high-potential leadership candidates are trustworthy; open-minded; learn from mistakes; have vision; display, courage, integrity, and passion; and are driven by values. While some good candidates were admitted into leadership pools, from our experience there was no determination if those individuals had the proper dispositions, admission was predicated on completing generic leadership training and tasks documenting minimal competency with state standards.

Rothwell (2005) focused substantially on building talent from within the organization, and delineated the identification high-quality, internal candidates as an essential component to quality succession planning. However, simply promoting from within the organization is not an indication of success. When Thomas (2011) interviewed senior school leaders, each asserted quality succession management was evident because all leadership vacancies were filled by internal candidates. When challenged to provide empirical data for success, none could. From our experience, the same postulate holds true, senior district leaders contended success because most vacancies were filled by internal candidates, yet there were no metrics for actual success. Far too often, we had observed the incorrect individual being promoted to a leadership position with the inevitable decline in student performance-sometimes dramatically.

Albeit of far greater importance in major business setting, cross-functional assessment talent is needed (Beeson, 1998). All of the authors had experience with school leaders who had strength in one curricular area and absolutely no competence in another. The former principal had once worked with a school leader who had a background in secondary mathematics, but did not even understand language arts standards and therefore had no clue when the standards were not being addressed by the appropriate teachers. Worse yet, one of the current school leaders had experience with another school leader who taught cocurricular courses and had no understanding of instructional leadership. The assistant principal described cross-functional procedures as "almost non-existent, and that central-office administrators supervised others in areas about which they know nothing."

As many authors contended, a quality succession plan is designed to meet the future organizational needs (e.g., Beeson, 1998; Beglinger, 2013; Chavez, 2011; Griffith, 2012). Therefore, soliciting plans for future growth from all employees is an important facet. Yet, from our experiences, such discussion only occurred if a specific school principal took it upon him- or herself to have the requisite conversations with employees. Even worse, vacancies for senior- and executive-level positions were difficult to fill because no internal candidates had the necessary experience or skillset to be successful in the position. Thus, providing evidence that proper leadership identification was almost nonexistent. 


\section{Implications}

Although not generalizable to a substantial degree, current school leaders at various levels can use the findings to assess leadership identification processes. Furthermore, faculty members in educational leadership preparation programs need to prepare students to navigate the "political waters" of the organizations in which their students will be employed. Educators at all levels can use the findings as a clarion to learn about the best practices in leadership identification and quality succession planning. For greater assistance in reviewing the processes, Parfitt (2017a) created a quantitative instrument to assess perceptions and familiarity with succession-planning aspects, and a forthcoming book will expand upon the process and provide a framework and suggested guidelines (Parfitt, 2021).

\section{Recommendations for Future Research}

Based on the results in conjunction with the limitations of the study, we recommend future research include:

- Expanding the scope of the research, possibly as a phenomenology or case study;

- Consider replicating the study in a wider geographic area and with additional participants;

- Examine school- and district-based recruitment practices and developmental components;

- To refine the scope including determining "what characteristics do individuals identified for leadership positions exhibit?"

By strengthening processes for talent identification, there is greater likelihood of having proper individuals serving in positions as school leaders. As Marzano et al. (2005) found, the principal is responsible for a .25 effect size in student achievement. Using state systems that contain letter grades for schools, having the proper individual serving as principal can raise a failing school to a $\mathrm{C}$ or a $\mathrm{C}$ school to an $\mathrm{A}$. Conversely, having an improper person serve as principal can lower the grade for an A school to a $\mathrm{C}$ school to failing. No matter the current situation, every student in school deserves the very best.

\section{References}

Beeson, J. (1998). Succession planning: Building the management corps. Business Horizons, 41(5), 61-66.

Beeson, J. (2000). Succession planning: Leading-edge practices: What the best companies are doing. Across the Board, 37(2), 38-41.

Beglinger, J. E. (2013). Designing tomorrow: Creative and effective succession planning. Journal of Nursing Administration, 43(10), 495-496. doi:10.1097/NNA.0b013e3182a3e85b

Brittingham, S. L. (2009). Principal succession in a fast-growing district. School Administrator, 66(11), 22-23.

Chang, H. (2008). Autoethnography as method. Walnut Creek, CA: Left Coast Press.

Chang, H., Longman, K. A., \& Franco, M. A. (2014). Leadership development through mentoring in higher education: A collaborative autoethnography of leaders of color. Mentoring and Tutoring: Partnership in Learning, 22(4), 373-389.

Chang, H., Ngunjiri, F. W., \& Hernandez, K. C. (2013). Collaborative autoethnography. Walnut Creek, CA: Left Coast Press.

Chavez, J. (2011). The case for succession planning. Strategic Finance, 92(8), 15-16. 
Conger, J. A., \& Fulmer, R. M. (2003). Developing your leadership pipeline. Harvard Business Review, 81(12), 7684.

Creswell, J. W. (2013). Qualitative inquiry and research design: Choosing among five approaches ( $3^{\text {rd }}$ ed.). Thousand Oaks, CA: Sage Publications.

Denzin, N. K., \& Lincoln, Y. S. (2005). Introduction: The discipline and practice of qualitative research. In N. K. Denzin \& Y. S. Lincoln (Eds.), The Sage Handbook of Qualitative Research (4 ${ }^{\text {th }}$ ed.) (pp. 1-19). Thousand Oaks, CA: Sage.

Durden, P. C., Izquierdo, J., \& Williams, J. A. (2008). Out of the ashes: Building leadership and sustainability amid the chaos. AASA Journal of Scholarship and Practice, 5(3), 47-52.

Ellis, C., Adams, T. E., \& Bochner, A. P. (2011). Autoethnography: An overview. Historical Social Research, 36(4), 273-290. doi:10.12759/hsr.36.2011.4.273-290

Ellis, C., \& Bochner, A. P. (2000). Autoethnography, personal narrative, reflexivity: Researcher as subject. In N. K. Denzin \& Y. S. Lincoln (Eds.), Handbook of Qualitative Research ( $2^{\text {nd }}$ ed.) (pp. 733-768). Thousand Oaks, CA: Sage Publications.

Englander, M. (2012). The interview: Data collection in descriptive phenomenological human scientific research. Journal of Phenomenological Psychology, 43(1), 13-35. doi:10.1163/156916212X632943

Fullan, M. (2005). Sustainable leadership. Thousand Oaks, CA: Corwin Press.

Golafshani, N. (2003). Understanding reliability and validity in qualitative research. The Qualitative Report, 8(4), 597-607. Retrieved from http://www.nova.edu/ssss/QR/QR8-4/golafshani.pdf

Griffith, M. B. (2012). Effective succession planning in nursing: A review of the literature. Journal of Nursing Management, 20(7), 900-911. doi:10.1111/j.1365-2834.2012.01418.x

Gurchiek, K. (2015, November 15). Don't leave succession planning to chance. Alexandria, VA: Society for Human Resource Management. Retrieved from https://www.shrm.org/resourcesandtools/hr-topics/organizationaland-employee-development/pages/leadership-many-organizations-fail-at-succession-planning.aspx

Hargreaves, A. (2005). Leadership succession. The Educational Forum, 69(2), 163-173. doi:10.1080/00131720508984680

Hengel, R. I. (2007). Leadership capacity: Planning for leadership succession in schools (Master's thesis). Available in ProQuest Dissertation and Theses Global database. (UMI No. 304719536)

Hernandez, K. C., Chang, H., \& Ngunjiri, F. W. (2017). Collaborative autoethnography as multivocal, relational, and democratic research: Opportunities, challenges, and aspirations. Auto/Biography Studies, 32(2), 215-254. doi:10.1080/08989575.2017.1288892

Marshall, C., \& Rossman, G. B. (1999). Designing qualitative research ( $3^{\text {rd }}$ ed.). Thousand Oaks, CA: Sage.

Marzano, R. J., Waters, T., \& McNulty, B. A. (2005). School leadership that works: From research to results. Alexandria, VA: Association for Supervision and Curriculum Development.

Maso, L. (2001). Phenomenology and ethnography. In P. Atkinson, A. Coffey, S. Delamont, J. Lofland, \& L. Lofland (Eds.), Handbook of Ethnography (pp. 136-144). Thousand Oaks, CA: Sage.

McCall, M. W., Jr. (1997). High flyers: Developing the next generation of leaders. Boston, MA: Harvard Business School Press.

McDonald, P. (2015, August 27). Few employees waiting in the wings: Survey suggests succession plans lacking at all levels. Menlo Park, CA: Robert Half Management Resources. Retrieved from https://www.prnewswire.com/news-releases/few-employees-waiting-in-the-wings-survey-suggestssuccession-plans-lacking-at-all-levels-300133964.html

Mendez, M. (2013). Autoethnography as a research method: Advantages, limitations and criticisms. Colombian Applied Linguistics Journal, 15(2), 279-287.

Muncey, T. (2010). Creating autoethnographies. Los Angeles, CA: Sage.

Ngunjiri, F. W., Hernandez, K. C., \& Chang, H. (2010). Living autoethnography: Connecting life and research [Editorial]. Journal of Research Practice, 6(1), 1-15. Retrieved from http://jrp.icaap.org/index.php/jrp/article/view/241/186

Parfitt, C. M. (2017a). Creating a succession-planning instrument for educational leadership. Education Leadership Review, 18(1), 21-36. Retrieved from https://www.icpel.org/ uploads/1/5/6/2/15622000/elr_volume_18_number_1_fall_2017.pdf

Parfitt, C. M. (2017b). Perceptions of succession planning in four Florida school districts: A mixed-method study. Southeast Journal of Educational Administration, 17(2), 88-115. Retrieved from https://www.srcea.co/southeast-journal

Parfitt, C. M. (2021). Succession planning: A framework and guidelines for school leaders. Lantham, MD: Rowman and Littlefield. Manuscript in preparation. 
Parfitt, C. M., Rea, D. C., Carter, C. F., Wilkerson, J. R., Rose, A. L., \& Valesky, T. C. (2019). Assessing leadership dispositions: Does explicit instruction matter? Southeast Journal of Educational Administration, 19(1), 67-77. Retrieved from https://www.srcea.co/southeast-journal

Parfitt, C. M., Rea, D. C., Carter, C. F., Wilkerson, J. R., \& Valesky, T. C. (2017a). Scaling of educational leadership candidates' commitment to national standards: The ELCBS Scale. Southeast Journal of Educational Administration, 17(2), 60-70. Retrieved from https://www.srcea.co/southeast-journal

Parfitt, C. M., Rea, D. C., Carter, C. F., Wilkerson, J. R., \& Valesky, T. C. (2017b). Using dispositional surveys to improve individual and program quality in educational leadership. Journal of Ethnic and Cultural Studies, 4(2), 81-87. Retrieved from http://www.ejecs.org/index.php/JECS/article/view/77/pdf

Parfitt, C. M., \& Rose, A. L. (2020). Informal mentoring for aspiring school leaders: A phenomenological study. Mentoring and Tutoring: Partnership in Learning, 28(3), 278-294, doi: 10.1080/13611267.2020.1778837

Rea, D. C., Carter, C. F., Wilkerson, J. R., Valesky, T. C., \& Lang, W. S. (2011). Assessing ISLLC-based dispositions of educational leadership candidates. International Journal of Educational Leadership Preparation, 6(3), 1-14. Retrieved from https://cnx.org/contents/tvWfIdfL@3/Assessing-ISLLC-BasedDisposit

Rothwell, W. J. (2005). Effective succession planning: Ensuring leadership continuity and building talent from within ( $3^{\text {rd }}$ ed.). New York, NY: AMACOM.

Russell, J. L., \& Sabina, L. L. (2014). Planning for principal succession: A conceptual framework for research and practice. Journal of School Leadership, 24(4), 599-634.

Sabina, L. L., \& Colwell, C. (2018). Challenges of principal succession: Examining the challenges of hiring internal vs. external candidates. Athens Journal of Education, 5(4), 375-396.

Smeltzer, C. H. (2002). Succession planning. Journal of Nursing Administration, 32(12), 615.

Strauss, A. L., \& Corbin, J. M. (1998). Basics of qualitative research: Grounded theory procedures and techniques ( $2^{\text {nd }}$ ed.). Thousand Oaks, CA: Sage.

Thomas, J. G. (2011). Exploring succession leadership training for continuity of leadership in selected K-12 school jurisdictions in Alberta (Doctoral dissertation). Available from ProQuest Dissertation and Theses Global database. (UMI No. 3674163)

Wilkerson, J. R., \& Lang, W. S. (2007). Assessing teacher dispositions: Five standards-based steps to valid measurement using the DAATS model. Thousand Oaks, CA: Corwin Press.

Wilkerson, J. R., \& Lang, W. S. (2011). Standards-based teacher dispositions as a necessary and measurable construct. The International Journal of Educational and Psychological Assessment, 7, 34-54. 